\title{
METODOLOGIAS ATIVAS E PARTICIPATIVAS EM UMA DISCIPLINA DE EDUCAÇÃO AMBIENTAL NO ENSINO SUPERIOR
}

\author{
Daniel Fonseca de Andrade ${ }^{1}$ \\ Tainá Figueroa Figueiredo²
}

Resumo: Este trabalho visa colaborar com as discussões sobre o uso de metodologias ativas e participativas em disciplinas de Educação Ambiental no ensino superior. Especificamente, visa compreender como os estudantes dessa disciplina relacionaram a experiência da metodologia a sua aprendizagem, e como essa relação se associa a princípios e objetivos da Educação Ambiental. Através da análise do discurso de textos desses estudantes, identificou-se que as metodologias favoreceram a emergência de um ambiente democrático e participativo, a construção e o fortalecimento de valores, habilidades e competências, e o alcance de objetivos afetivo-emocionais, muitos dos quais propostos por diretrizes da Educação Ambiental brasileira.

Palavras-chave: Sala de Aula Invertida; Participação; Ensino-Aprendizagem; Processos Formativos.

Abstract: This research aims at collaborating on the debate over the use of participatory active methodologies in environmental education programs in higher education. Specifically, it aims at understanding how students in a program related their experiences with the methodologies to their learning, and how this relation was associated to principles and objectives of environmental education. Through discourse analysis, it was identified that the methodologies favored the emergency of a democratic and participatory environment, the creation and strengthening of values, skills and competencies, and the achievement of affective and emotional objectives, many of which put forth by Brazilian environmental education guidelines.

Keywords: Flipped Classroom; Participation; Teaching-Learning, Teaching Processes

\footnotetext{
${ }^{1}$ Universidade Federal do Estado do Rio de Janeiro. E-mail: daniel.andrade@unirio.br, Link para o Lattes: http://lattes.cnpq.br/7825501663911868

2 Universidade Federal do Rio de Janeiro. E-mail: tainaff12@gmail.com

Link para o Lattes: http://lattes.cnpq.br/3684853984365132
} 


\section{Introdução}

A Educação Ambiental (EA) é um campo do conhecimento em desenvolvimento no Brasil desde a década de 1970. Ao longo do tempo, amadureceu (REIGOTA, 1998), se ampliou e se diversificou, formando identidades plurais (LAYRARGUES, 2004).

Mesmo em meio a essa diversidade, a institucionalização da EA direcionou os rumos do campo para um caminho que valoriza a democracia, a participação, o diálogo, o pluralismo de ideias e concepções pedagógicas, a solidariedade, a cooperação, e que objetiva a formação do pensamento crítico, integrado e de uma atitude participativa nos contextos educativos (BRASIL, 1999). Tais características, presentes na Política Nacional de Educação Ambiental (PNEA), foram reafirmadas em diferentes edições do Programa Nacional de Educação Ambiental (BRASIL, 2005; 2018).

Do ponto de vista do ensino formal, incluindo-se aí o superior, a EA está prevista na Política Nacional do Meio Ambiente (BRASIL, 1981), na Constituição Federal (BRASIL, 1988) e na PNEA (BRASIL, 1999). Entretanto, seu detalhamento se deu nas Diretrizes Curriculares Nacionais em Educação Ambiental (BRASIL, 2012), que reafirmou princípios e objetivos anteriormente detalhados e destacou o papel político transformador, emancipatório e ético da EA.

A EA coloca, assim, o desafio de se criarem ambientes pedagógicos que partam dos princípios e busquem os objetivos descritos acima, propícios à vivência democrática, participativa, plural, dialógica, transformadora, emancipatória, ética e cidadã, e que estimulem o pensamento crítico e integrado. Nesse sentido, incita educadores a criar práticas pedagógicas que vão além da transmissão passiva de informações e que sejam coerentes com o próprio discurso (MORAN, 2015), estimulando a afetividade (PAYNE et al. 2018), o reconhecimento da alteridade (SATO; QUADROS; KAWAHARA, 2018) e a construção de valores, conhecimentos, atitudes, habilidades e competências relativas à questão ambiental (BRASIL, 2018; CARVALHO, 2012).

A questão que se coloca é: que tipo de metodologia poderia criar tais ambientes? Há indícios que as metodologias ativas têm esse potencial, o que já foi constatado para outros campos do conhecimento como Ciências da Saúde (GÓMEZ-POYATO, 2019), Microbiologia (RODRíGUES et al. 2019), Farmacologia (CARSTENSEN et al. 2020), Direito, Ciências Sociais, Engenharia, Arquitetura (GALINDO-DOMÍNGUEZ; BENZANILLA, 2019), Medicina, Administração de Empresas, Educação, Enfermagem, Computação, Estatística, Biologia, Ciências (LUCENA et al. 2019), Física e Química (GÓMEZ-POYATO, 2019; LUCENA et al. 2019). No âmbito deste trabalho, no entanto, fica evidenciada uma lacuna relativa ao uso de metodologias ativas no ensino superior em disciplinas de Educação Ambiental. 
É nesse contexto que se insere o presente trabalho. O seu objetivo geral é colaborar com a geração de conhecimento acerca do uso de metodologias ativas e participativas em disciplinas de Educação Ambiental no ensino superior. Especificamente, esta pesquisa visa compreender como os estudantes de uma disciplina de Educação Ambiental no ensino superior relacionaram a experiência da metodologia a sua aprendizagem, e como essa relação se associa a princípios e objetivos do campo da Educação Ambiental.

São duas as justificativas para esta pesquisa. A primeira, apesar de haver grande número de evidências sobre os benefícios das metodologias ativas no ensino superior, para Du et al. (2020), elas não são ainda suficientes. Estudos são necessários porque as evidências existentes são relativas a contextos específicos, que são instigantes, mas que não garantem que os processos e resultados de uma situação sejam transpostos a outras (MICHAEL, 2006). A segunda, como o campo da Educação Ambiental demanda práticas pedagógicas que permitam 0 desenvolvimento de competências e valores, é preciso que se verifique a adequação das metodologias ativas especificamente para ele.

\section{Metodologias ativas: tessituras teóricas}

Durante muito tempo, o ensino superior foi marcado quase que exclusivamente por aulas expositivas, unidirecionais (MARTINS et al. 2019) e centradas no conteúdo, descritas por Freire (1987) como bancárias. Mais recentemente, porém, as lógicas centradas nos professores e, portanto, na transmissão de conteúdo, estão dando espaço para lógicas centradas nos alunos, ou na aprendizagem (MICHAEL, 2006; LIN; HWANG, 2018; PINTADO; ROBAS; REY-BALTAR, 2018; GÓMEZ-POYATO, 2019; MARTINS et al. 2019; WILTBANK et al. 2019). Para tal, muitos docentes têm adotado o que se convencionou chamar, de forma genérica, de metodologias ativas (PINTADO; ROBAS; REY-BALTAR, 2018).

Segundo Pintado, Robas e Rey-Baltar (2018), uma metodologia é "um conjunto de oportunidades, situações, técnicas e condições que se coloca a serviço do alunato, organizados de maneira sistemática e intencional e que, ainda que não promovam diretamente a aprendizagem, facilitam que ela ocorra" (p. 121). Toda metodologia de ensino possui uma orientação filosófica subjacente (MARTINS et al. 2019; GUASP; MEDINA; AMENGUAL, 2020; HERNÁNDEZ; ORTIZ; ABELLÁN, 2020), que externaliza as intenções educativas, as premissas didáticas, a concepção de educação e de aluno por parte dos docentes, assim como seus conhecimentos sobre os elementos curriculares (GUASP; MEDINA; AMENGUAL, 2020).

Nesse contexto, as metodologias ativas são aquelas que, como definição geral, engajam os estudantes mentalmente e, muitas vezes, fisicamente, com seus próprios processos de aprendizagem (MICHAEL, 2006; PINTADO; ROBAS; REY-BALTAR, 2018; RODRÍGUES et al. 2019; MARTINS 
et al. 2019; BISSOTO; CAIRES, 2019; GIOIOSA; KINKELA, 2019; WILTBANK et al. 2019; HERNÁNDEZ; ORTIZ; ABELLÁN, 2020), "na orquestração de atividades de aprendizagem e na dinamicidade das situações nas quais 0 conhecimento é construído, empregado, avaliado e reconstruído" (BISSOTO; CAIRES, 2019, p. 170).

Apesar de existir um extenso rol de metodologias consideradas ativas (PINTADO; ROBAS; REY-BALTAR, 2018; MARTINS et al. 2019; BISSOTO; CAIRES, 2019; GIOIOSA; KINKELA, 2019), para Bissoduto e Caires (2019), elas compartilham algumas características fundamentais: são propostas epistemológicas com inspirações construtivistas, que consideram os conhecimentos prévios dos alunos e sua motivação, a conexão entre a teoria e a prática, focam no processo mais do que nos resultados e destacam a importância das competências. Além disso, as autoras ressaltam que o atributo 'ativo' das metodologias ativas precisa estar associado à intencionalidade dos estudantes, respeitando sua autonomia para planejar, querer fazer e querer ser. São também contextualizadas e reflexivas (PINTADO; ROBAS; REYBALTAR, 2018).

Assim, metodologias ativas buscam transcender as concepções que focam exclusivamente na memorização de conteúdos (BISSOTO; CAIRES, 2019) para estimular o desenvolvimento de funções cognitivas mais complexas. São várias encontradas na literatura, entre elas o pensamento crítico (LIN; HWANG, 2018; POLO et al. 2019; RODRÍGUEZ et al. 2019; WILTBANK et al. 2019; ZAMAR; SEGURA, 2020; GUASP; MEDINA; AMENGUAL, 2020), a autonomia (DÍAZ; MARTÍN, 2018; MARTINS et al. 2019; GUASP; MEDINA; AMENGUAL, 2020), o protagonismo (PINTADO; ROBAS; REY-BALTAR, 2018; POLO et al. 2019; GUASP; MEDINA; AMENGUAL, 2020), a criatividade (RODRÍGUES et al. 2019; POLO et al. 2019) e a metacognição (PINTADO; ROBAS; REY-BALTAR, 2018).

Portanto, proponentes das metodologias ativas consideram que a aprendizagem não se dá por mera transferência de conhecimento (MICHAEL, 2006; CARSTENSEN et al. 2020), mas exige um exercício mental (MICHAEL, 2006) para a construção e reconstrução das representações e interpretações da realidade por meio da ação e do discurso (FORMENTI; JORIO, 2019). É esse exercício mental que atribui a ela seu caráter ativo (BISSOTO; CAIRES, 2019).

Além disso, as metodologias ativas visam à construção de conhecimentos significativos (MICHAEL, 2006; PINTADO; ROBAS; REYBALTAR, 2018; GUASP; MEDINA; AMENGUAL, 2020), ou seja, conhecimentos cujos sentidos são atribuídos pelos estudantes no processo de aprendizagem (BISSOTO; CAIRES, 2019), e de competências, compreendidas como a combinação de conhecimentos, habilidades, talentos, atitudes e valores (BEZANILLA et al. 2019; ZAMAR; SEGURA, 2020).

Dentre as várias metodologias ativas possíveis, uma que tem se 
2018). As SAl são formatos pedagógicos que reorganizam as atividades realizadas pelos estudantes e os locais onde são realizadas (GÓMEZPOYATO, 2019; LUCENA et al. 2019). Ao mesmo tempo, alteram os papéis desempenhados por docentes e estudantes (MICHAEL, 2006; LUCENA et al. 2019; ZAMAR; SEGURA, 2020; GUASP; MEDINA; AMENGUAL, 2020). Enquanto em aulas tradicionais os estudantes, em geral, têm o primeiro contato com um conteúdo por meio de uma exposição docente, na SAl esse primeiro contato se dá previamente à aula, através de material organizado pelo docente, e o momento presencial é utilizado para outras atividades não expositivas (SCHULTZ et al. 2014; LIN; HWANG, 2018; DÍAZ; MARTÍN, 2018; GÓMEZPOYATO, 2019; POLO et al. 2019; LUCENA et al. 2019; ZAMAR; SEGURA, 2020).

Embora esse modelo invertido seja comum em diferentes iniciativas, o formato do material a ser estudado previamente e as atividades desenvolvidas em sala variam consideravelmente. Por exemplo, antes da aula os estudantes podem assistir a vídeos, fazer revisões ou pré-testes (LIN; HWANG, 2018), leituras, reflexões (ZAMAR; SEGURA, 2020) ou ainda consultas a materiais digitais (SCHULTZ et al. 2014). Já na sala, podem usar o tempo da aula para dirimir dúvidas (DÍAZ; MARTíN, 2018; POLO et al. 2019; LUCENA et al. 2019; ZAMAR; SEGURA, 2020), fazer atividades em grupo (GÓMEZ-POYATO, 2019; LUCENA et al. 2019), participar de jogos (GÓMEZ-POYATO, 2019) e etc. Como visto, as SAI podem ser combinadas com outras metodologias ativas. Assim, apesar de muitas iniciativas se utilizarem das SAI, o que é feito em cada uma delas pode ser completamente diferente. De qualquer maneira, há autores que argumentam que as SAI permitem uma maior interação dos estudantes com o conteúdo, o que potencializa a aprendizagem (GÓMEZ-POYATO, 2019) e consolida o conhecimento (RODRÍGUEZ et al. 2019).

Uma das consequências práticas do formato das SAI é atribuir ao estudante responsabilidade pela sua aprendizagem (MARTINS et al. 2019; LUCENA et al. 2019) e estimulá-lo a ter papel ativo ao longo do processo (MICHAEL, 2006; GÓMEZ-POYATO, 2019; MARTINS et al. 2019; WILTBANK et al, 2019; HERNÁNDEZ; ORTIZ; ABELLÁN, 2020). Outra é deslocar o docente, do papel de provedor de informações, para o de facilitador da aprendizagem (PINTADO; ROBAS; REY-BALTAR, 2018; MARTINS et al. 2019; GÓMEZ-POYATO, 2019; LUCENA et al. 2019; ZAMAR; SEGURA, 2020). Docentes e alunos tornam-se, portanto, corresponsáveis pelo processo de ensino-aprendizagem (ZAMAR; SEGURA, 2020).

Por fim, a exemplo de outras metodologias ativas, estudos evidenciam que a implementação das SAI no ensino superior favorece o desenvolvimento de competências, como a comunicação (ZAMAR; SEGURA, 2020), a capacidade de resolução de problemas, a autonomia (GUASP; MEDINA; AMENGUAL, 2020) e o pensamento crítico (ZAMAR; SEGURA, 2020; GUASP; MEDINA; AMENGUAL, 2020). 


\section{Contexto da pesquisa}

Esta pesquisa foi realizada em uma turma da disciplina de Educação Ambiental e Cidadania oferecida por uma universidade federal brasileira, no segundo semestre de 2017. Estavam matriculados nessa turma, 31 estudantes provenientes de oito cursos de graduação. A disciplina tem uma carga horária de 45 horas/aula que são distribuídas em 15 semanas, com três horas em cada encontro. Detalhes sobre a concepção teórico-metodológica da disciplina podem ser encontrados em Andrade e Figueiredo (2019).

A disciplina foi organizada de forma invertida, com estudantes tendo acesso ao conteúdo previamente às aulas e com os encontros presenciais sendo realizados por meio de diferentes metodologias ativas e participativas, como o café mundial, o aquário e a linha do tempo (TEIXEIRA; DUARTE; MORIMOTO, 2007). A avaliação da disciplina se deu de duas formas: (i) por seis trabalhos realizados individual e coletivamente ao longo do semestre; (ii) por um trabalho final, em que os estudantes teceram uma redação na qual responderam à questão 'o que você aprendeu com a disciplina de Educação Ambiental e Cidadania?'. Para os propósitos desta pesquisa, foi realizada uma análise dessa redação final, com foco específico para os aspectos relativos à metodologia da disciplina.

A escolha das redações finais como objeto da investigação partiu do pressuposto de que a linguagem produz significados, ações e identidades (GEE, 2011). Também, que a narrativa de uma experiência vivida permite uma reflexão sobre esse vivido, na qual os autores escolhem o que deve e o que não deve ser incluído (SOUZA; OLIVEIRA, 2016). Assim, consideramos que menções às metodologias ativas e participativas da disciplina, que os autores decidiram espontaneamente incluir nos textos, oferecem indícios para a compreensão sobre como que os estudantes as experienciaram.

\section{Metodologia}

O contexto mencionado acima foi onde a comunicação e as experiências pedagógicas ocorreram. Esse espaço físico e temporal compôs um ambiente de compartilhamento de narrativas e de produção de discursos.

O corpus de análise é composto por 31 textos nos quais os estudantes escreveram sobre o que aprenderam na disciplina. Esses trabalhos foram organizados em ordem alfabética e numerados de 1 a 31 , a fim de se preservar suas identidades. Esses textos foram analisados a partir da análise de discurso (GEE, 1991; 2011). Para Gee (1991), o texto narrativo possui uma estrutura flexível e complexa que permite a construção de uma imagem mental tanto nos autores, quanto nos receptores das mensagens.

Ao ler os textos, destacamos apenas os momentos textuais (frases, linhas e parágrafos) que abordavam a metodologia da disciplina ou elementos relacionados a ela. Além disso, nos orientamos pelos elementos dêiticos, que 
são "palavras cuja referência é determinada pelo contexto" (GEE, 2011, p. 8) e indicam tempo, espaço e sujeito no discurso (KOELLING, 2003). São basicamente pronomes, verbos e advérbios que ajudam a situar e compreender sujeitos e discursos.

Posteriormente, os momentos textuais foram organizados em unidades de ideias (GEE, 2011), que são pequenos blocos de informação sobre algum acontecimento, perspectiva e tema (GEE, 1991). Esses momentos textuais podem ser constituídos por palavras ou pequenas frases, e podem conter mais de uma unidade de ideia (GEE, 2011).

\section{Resultados e discussão}

\section{Como os estudantes da disciplina relacionaram a experiência da metodologia a sua aprendizagem?}

Foram criadas as seguintes unidades de ideias relacionadas à vivência dos estudantes com as metodologias ativas e participativas da disciplina: crítica ao ensino tradicional; arranjo da sala; horizontalidade; diversidade; estar com o outro; pensamento crítico; relação metodologia-conteúdo; críticas; e mudanças/autoanálise.

O quadro 1 apresenta as nove unidades de ideias, seguidas do número de narrativas de estudantes que se relacionaram a elas, entre parênteses (coluna 1), e de excertos que as ilustram (coluna 2), identificados pelo número do estudante e o seu respectivo curso de graduação. Por uma questão de espaço, foram inseridos apenas alguns trechos ilustrativos de cada unidade de ideia. Por fim, nos momentos textuais, destacamos em itálico aqueles relacionados às unidades de ideia e em negrito os elementos dêiticos.

Quadro 1. Unidades de ideia e momentos textuais que as exemplificam

\begin{tabular}{|c|c|}
\hline $\begin{array}{c}\text { Unidade de } \\
\text { ideia }\end{array}$ & Momentos textuais dos estudantes da disciplina (excertos) \\
\hline $\begin{array}{l}\text { Crítica ao } \\
\text { ensino } \\
\text { tradicional } \\
\text { (6) }\end{array}$ & $\begin{array}{l}\text { "Ao entrar no ambiente da faculdade confesso que fiquei um pouco } \\
\text { decepcionada. Bem diferente do que vinha vivenciando no colégio, me } \\
\text { observei em um formato de aula na qual apenas um professor fala na frente de } \\
\text { um projetor e uma sala com cerca de quarenta pessoas sentadas em fileiras } \\
\text { que apenas escutam, anotam, dormem, mexem na Internet, etc.." (Est. 2, } \\
\text { LCB). } \\
\text { "Me senti como parte da aula e não apenas como uma antena receptora ou um } \\
\text { depósito de arquivos" (Est. 20, CA). } \\
\text { "As leituras e os debates em sala de aula construíram uma nova percepção } \\
\text { sobre determinados assuntos, por exemplo, eu nunca tinha parado para refletir } \\
\text { sobre a educação bancária imposta a sociedade desde os primórdios do } \\
\text { ensinamento da escola até o ensino superior, ou seja, algo fundamental para a } \\
\text { construção de uma pessoa como pensador em meio à sociedade, que é o ato } \\
\text { de questionar os ensinamentos que são passados, seja na escola ou na } \\
\text { faculdade, é retirado do ser humano desde criança" (Est. 30, CB). }\end{array}$ \\
\hline
\end{tabular}

Continua... 
...continuação.

\begin{tabular}{|c|c|}
\hline $\begin{array}{l}\text { Unidade de } \\
\text { ideia }\end{array}$ & Momentos textuais dos estudantes da disciplina (excertos) \\
\hline $\begin{array}{l}\text { Arranjo da } \\
\text { Sala (8) }\end{array}$ & $\begin{array}{l}\text { "Os alunos, ao invés de serem organizados no modo tradicional, em fileiras } \\
\text { e o professor falando na frente, foram organizados durante as aulas em rodas } \\
\text { de debate. Com isso, todos ficaram a mesma altura, alunos e professor, } \\
\text { trocando ideias e todos participando de debates e discussões" (Est. 10, } \\
\text { CB). } \\
\text { "Nessa disciplina foi diferente, sempre sentamos em roda, para que todos } \\
\text { tivessem a visão de todos os colegas e para que o professor não seja a } \\
\text { figura mais importante da sala de aula" (Est. 19, CN). } \\
\text { "Além disso, as aulas me provocaram o interesse pelo debate com o } \\
\text { próximo sobre os diversos assuntos passados, e a visão de que não } \\
\text { importa se a opinião do seu colega for muito semelhante ou divergir muito } \\
\text { da sua própria opinião, o que deve se levar em consideração é a discussão } \\
\text { para criação de ideia e, então, abrir a mente para novas opiniões e ideias - } \\
\text { para isso, o mecanismo de sentar todos em uma roda gigante em sala de } \\
\text { aula foi fundamental para o debate e a fuga da educação clássica bancária" } \\
\text { (Est. } 30, \mathrm{CB} \text { ). }\end{array}$ \\
\hline $\begin{array}{l}\text { Horizontali- } \\
\text { dade (9) }\end{array}$ & $\begin{array}{l}\text { "Desde o primeiro dia de aula já achei interessante a forma como o } \\
\text { [professor] conduzia a aula. Organizava a sala em uma grande roda ao } \\
\text { invés de ir para frente da sala, como tradicionalmente fazem os professores, } \\
\text { ele sentou-se numa das cadeiras comuns, no final da sala, pediu para que } \\
\text { nos apresentássemos e disse que tudo que falássemos deveria ser } \\
\text { ouvido por cada um da sala, e não apenas por ele. Dessa forma ele tirava a } \\
\text { atenção e o protagonismo do docente, e punha no aluno, que deve ser o } \\
\text { foco da disciplina" (Est. } 6 \text {, CB). } \\
\text { "A partir daí, passei entender e valorizar a metodologia aplicada pela } \\
\text { equipe responsável pela disciplina, onde se dá oportunidade para todos } \\
\text { participarem, instiga o debate e o crescimento coletivo, além de tentar } \\
\text { tornar a relação educador-educando a mais horizontal possível" (Est. } 5 \text {, CA). } \\
\text { "O mais incrível da disciplina para mim foi o fato dela ter sido construída em } \\
\text { conjunto professor-alunos, onde as opiniões e discussões de todos foram } \\
100 \% \text { valorizadas e agregadoras do nosso processo educacional" (Est. 17, } \\
\text { CA). } \\
\text { "Nessa disciplina foi diferente, sempre sentamos em roda, para que todos } \\
\text { tivessem a visão de todos os colegas e para que o professor não seja a } \\
\text { figura mais importante da sala de aula" (Est. 19, CN). }\end{array}$ \\
\hline $\begin{array}{l}\text { Diversidade } \\
\text { (7) }\end{array}$ & $\begin{array}{l}\text { "Questões sobre o perigo de uma história, contada por apenas um olhar, a } \\
\text { valorização do diferente passaram a fazer parte da minha construção de } \\
\text { pensamento. Essa questão se deu nas aulas, onde tínhamos uma grande } \\
\text { diversidade de pessoas, cursando diversos grupos e todos acrescentaram } \\
\text { em todas as discussões" (Est. 5, CA). } \\
\text { "A pluralidade de intenções, aprendizado e matéria humana foi dos pontos } \\
\text { mais marcantes nas aulas. Conviver por } 4 \text { meses com pessoas de diversos } \\
\text { cursos, com origens, aspirações, idades e histórias de vida completamente } \\
\text { diferentes já é bastante rico, mas poder trocar com todos esses universos, } \\
\text { a partir de uma pedagogia não centrada no professor detentor e passador de } \\
\text { conteúdo foi um passo a mais" (Est. 3, CA). }\end{array}$ \\
\hline
\end{tabular}

Continua... 
...continuação.

\begin{tabular}{|c|c|}
\hline $\begin{array}{c}\text { Unidade de } \\
\text { ideia }\end{array}$ & Momentos textuais dos estudantes da disciplina (excertos) \\
\hline $\begin{array}{l}\text { Estar com o } \\
\text { outro (17) }\end{array}$ & $\begin{array}{l}\text { "Uma das grandes conquistas desse curso, para mim, foi um exercício raro } \\
\text { de empatia, compreensão e alteridade [...]". (Est.3, CA). } \\
\text { "As aulas provocativas e instigantes, incentivando a participação coletiva, as } \\
\text { dinâmicas entre os alunos, por muitas vezes deixava um certo desconforto } \\
\text { na turma. Foi interessante vivenciar. O desconforto e a incerteza causam } \\
\text { estranhamento, e é difícil lidar com essa situação. Mais especificamente, } \\
\text { tem sido bastante duro lidar com o outro" (Est.3, CA). } \\
\text { "É uma disciplina que exige presença, pois os assuntos são discutidos em } \\
\text { aula e debatidos entre os alunos e o professor. Portanto, não é um conteúdo } \\
\text { que é aprendido em casa. Claro que os assuntos discutidos estão presentes } \\
\text { nos temas dos trabalhos, porém os debates ricos que são feitos em sala de } \\
\text { aula não podem ser substituídos" (Est. 10, CB). } \\
\text { "Havia uma sensação de conforto" (Est. 13, CA). } \\
\text { "Cursando Edam me senti mais próximo do calor humano, que deveria estar } \\
\text { presente até mesmo nos espaços científicos, mas do qual a ciência parece } \\
\text { ter vontade de se afastar ao máximo" (Est. 20, CA). } \\
\text { "E acredito que o melhor que eu pude absorver do nosso tempo junto foi } \\
\text { poder reinterpretar o mundo junto com vocês e ter várias ideias e insights } \\
\text { que não havia tido antes, por não estar perto e convivendo com um grupo } \\
\text { ímpar dé pessoas". (Est. } 29 \text {, DI). } \\
\text { "[D]urante a maioria das aulas aprendia muito com os relatos e falas de } \\
\text { outros alunos, evidenciando que todos têm algo a acrescentar, e que o } \\
\text { diálogo é sempre o melhor caminho para chegar a uma conclusão, a um } \\
\text { consenso, mesmo quando as opiniões são conflitantes". (Est. } 6, \text { CB). } \\
\text { "Cada aula, cada texto, cada filme foi sem dúvida uma reflexão e gatilho para } \\
\text { mudanças de hábitos. E a forma com que isso foi realizado foi um } \\
\text { diferencial que nos permitiu fazer associações que sozinhos não seríamos } \\
\text { capazes, mas que em conjunto com os colegas se tornou óbvia". (Est. 17, } \\
\text { CA). }\end{array}$ \\
\hline $\begin{array}{l}\text { Pensamen- } \\
\text { to crítico (3) }\end{array}$ & $\begin{array}{l}\text { "O mais incrível da disciplina para mim foi o fato dela ter sido construída } \\
\text { em conjunto professor-alunos, onde as opiniões e discussões de todos } \\
\text { foram } 100 \% \text { valorizadas e agregadoras do nosso processo educacional. } \\
\text { Agora me pego pensando, e se todas as disciplinas forem construídas } \\
\text { dessa forma? Talvez teríamos chance de nos qualificar muito mais e de } \\
\text { obter uma experiência totalmente diferenciada na universidade e até nos } \\
\text { ensinos médio e fundamental. Talvez o tal do "pensamento crítico" deixasse } \\
\text { de ser coisa para os intelectuais e cientistas detentores de diplomas de } \\
\text { Ciências Sociais e afins e passasse a ser de todos, o que mudaria infinitos } \\
\text { aspectos de nossa sociedade." (Est. } 17, \mathrm{CA} \text { ). }\end{array}$ \\
\hline $\begin{array}{l}\text { Relação } \\
\text { Metodologia } \\
\text { /conteúdo } \\
\text { (9) }\end{array}$ & $\begin{array}{l}\text { "Uma das grandes conquistas desse curso, para mim, foi um exercício raro } \\
\text { de empatia, compreensão e alteridade, e de como essas práticas estão } \\
\text { diretamente ligadas a uma proposição ambiental, que necessita ser } \\
\text { holística, plural, coletiva, contraditória e propositiva". (Est., 3, CA) } \\
\text { "O primeiro ponto, e o mais importante, na minha opinião, que a disciplina me } \\
\text { ensinou foram as diferentes maneiras de se ter uma aula" (Est. 19, CN). } \\
\text { "A disciplina conseguiu transcender o modelo metódico e newtoniano que } \\
\text { ainda rege o nosso ensino superior mas sem negligenciar nenhum conteúdo } \\
\text { apresentado" (Est. 20, CA). }\end{array}$ \\
\hline
\end{tabular}

Continua... 
...continuação.

\begin{tabular}{|ll|}
\hline $\begin{array}{l}\text { Unidade de } \\
\text { ideia }\end{array}$ & \multicolumn{1}{c|}{ Momentos textuais dos estudantes da disciplina (excertos) } \\
Críticas (2) & "Por outro lado, a carga elevada de trabalhos me prejudicou. Em um certo \\
& momento do período, comecei a desanimar com a disciplina faltar e pensar \\
& em desistir" (Est. 16, MAT). \\
& "Mas a minha crítica quanto a isso é que, ao longo do semestre tive muitos \\
& trabalhos para fazer, provas para estudar, além do horário normal de \\
& trabalho, então para mim, realmente ficou pesado e não consegui dar conta \\
& de tudo" (Est. 19, CN). \\
\hline Mudanças/ & "Como desde criança assisto aulas que o texto de Paulo Freire classifica \\
Autoanálise & como bancária, a metodologia participativa da disciplina me causou uma \\
(4) & repulsa em primeiro momento. Mas após apresentar minha primeira prática \\
& pedagógica, fazer a leitura do texto de Paulo Freire e a discussão em sala, a \\
& diferença entre assistir aula e participar da aula ficou clara. Isso implicou \\
em mim um sentimento de sair da minha zona de conforto, de questionar, e \\
de realmente estar em sala de aula e agregar o que neste local era \\
discutido para minha vida. De realmente pensar sobre, entender, e não só \\
arquivar em memória, não só ouvir e guardar em mim algo que não fazia \\
parte de mim" (Est. 21, MAT). \\
"A compartilhar. Seja conhecimento, seja ideia. A dinâmica da disciplina \\
influenciou a minha forma de me comunicar com os outros. Sendo tímida \\
desde criança, sempre tive dificuldade em me expressar publicamente. No \\
entanto, nesse semestre senti uma evolução pessoal nesse quesito por \\
conta da necessidade de participar das discussões em sala de aula e \\
também ao precisar montar uma prática pedagógica que se ambientasse \\
fora da formalidade típica das universidades - uma pessoa à frente da turma, \\
discursando incessantemente gerando uma narrativa de mão única" (Est. \\
27, CA).
\end{tabular}

Fonte: Autoria própria.

Legenda: CA - Bacharelado em Ciências Ambientais; MAT - Licenciatura em Matemática; CN - Licenciatura em Ciências da Natureza; CB - Bacharelado em Ciências Biológicas; LCB Licenciatura em Ciências Biológicas; DI - Bacharelado em Direito.

Em consonância com Gallo (2017), as narrativas produzidas pelos estudantes mostraram-se heterogêneas em tamanho, abrangência, enfoque e conteúdo. Todas as trinta e uma, porém, fizeram referência à metodologia da disciplina. Isso é relevante para esta pesquisa porque tais menções foram espontâneas, respondendo a uma pergunta geral sobre a disciplina e não a uma questão específica sobre as metodologias. Da mesma forma, as referências às metodologias foram variadas, o que corrobora a ideia de que a mesma atividade é percebida de forma diferente pelos estudantes (WILTBANK et al. 2019).

A primeira unidade de ideia criada foi 'crítica ao ensino tradicional', que reúne momentos textuais das narrativas que criticam o bancarismo (FREIRE, 1987) a partir das vivências nas metodologias participativas. Mais especificamente, os momentos textuais inclusos nessa unidade se referiam ao arranjo da sala, à relação vertical entre educador-educando, ao papel dos estudantes e a comparações com a vida escolar pregressa. 
A crítica ao ensino tradicional feita por estudantes a partir da vivência de metodologias ativas foi também um resultado encontrado por Silva et al. (2014), que levantaram menções relativas ao rompimento com a cultura da memorização e da reprodução, e a atribuição de sentido ao estudar para além do aprender para atender a expectativa do professor. Isso é um indicativo de que metodologias ativas e participativas têm um potencial de, por si só, estimular reflexão quando comparadas com metodologias tradicionais, no caso, reflexão metodológica.

Outro destaque feito pelos estudantes, relacionado à metodologia da disciplina, referiu-se ao 'arranjo da sala', segunda unidade de ideia. Oito textos apontaram o modo de organização física variável dos estudantes e das cadeiras durante as aulas, que não ficavam enfileiradas, mas em rodas de diferentes tamanhos. Isso geralmente estava associado a relatos sobre 0 quanto esse arranjo foi diferente do vivenciado na vida escolar pregressa e em disciplinas na universidade. Ao mencionarem as cadeiras, alguns apontaram que isso favoreceu o protagonismo discente, a interação entre os estudantes nas discussões e a proximidade deles com o professor e monitora. Além disso, enfatizaram o arranjo variável como uma quebra do padrão de ensino tradicional, e relacionaram o desenfileiramento das cadeiras a uma afirmação política crítica ao ensino bancário (FREIRE, 1987).

Como coloca Kaufmann (2010), o arranjo do espaço legitima e promove uma ideologia. Da mesma forma, o contexto social exerce influência na maneira como os seus participantes nele se sentem e agem (LEWIN, 1989). Isso justifica a atenção para a configuração dos ambientes de aprendizagem (BISSOTO; CAIRES, 2019), que podem ser considerados facilitadores desse processo (BORBA; ALVES; CAMPAGNOLO, 2020). Justifica também redesenhá-los, para que, de forma multifuncional, fomentem a expressão e a ação dos estudantes, e favoreçam atividades individuais, coletivas e plenárias (MORAN, 2015).

Portanto, o arranjo da sala em roda gera uma percepção física, sensorial e visual de inclusão, pois todos se sentam lado a lado e se veem. Porém, estudantes mencionaram também a postura do professor, que se sentou na roda (e não na frente), ficou na mesma altura dos estudantes (e não mais alto) e enfatizou a importância do ouvir coletivo. Isso foi identificado como uma busca de construção de 'horizontalidade' tanto entre os estudantes, quanto entre estudantes e docente. 'Horizontalidade' é a terceira unidade de ideia construída nesta pesquisa, e foi destacada por nove estudantes em seus trabalhos.

Como pode ser visto acima, a aplicação das metodologias ativas e participativas ampliou o papel do docente, que deixou de ser mero provedor de informações para se tornar também facilitador de aprendizagem (PINTADO; ROBAS; REY-BALTAR, 2018; MARTINS et al. 2019; GÓMEZ-POYATO, 2019; LUCENA et al. 2019; ZAMAR; SEGURA, 2020), orientador e curador (MORAN, 2015). Para os discentes, esses aspectos favoreceram uma sensação de 
pertencimento, de inclusão e de participação em seu próprio processo de aprendizagem.

O 'arranjo da sala', portanto, disse respeito também ao ambiente propiciado pelo docente para a sua relação com os alunos e entre os alunos. Para Martins et al. (2019), Lucena et al (2019), Benzanilla et al. (2019) e Borba, Alves e Campagnolo (2020), a parceria e o comprometimento entre docentes e estudantes é fundamental para que esses se tornem parte ativa em sua aprendizagem, o que é a essência das metodologias ativas. Cria-se, com isso, um senso de corresponsabilidade (ZAMAR; SEGURA, 2020), pertencimento (BORBA; ALVES; CAMPAGNOLO, 2020) e de protagonismo (PINTADO; ROBAS; REY-BALTAR, 2018; POLO et al. 2019; GUASP; MEDINA; AMENGUAL, 2020) entre os envolvidos na disciplina.

A quarta unidade de ideia construída a partir das narrativas dos estudantes foi 'diversidade'. Inscritos nela estão trechos de sete estudantes que destacaram a percepção da 'diversidade' na sala de aula, relativa à diversidade de cursos e de pessoas (suas origens, idades e histórias de vida). Nos excertos, percebe-se como a diversidade na sala foi considerada um valor em si e como algo que colaborou para a aprendizagem.

A diversidade, potencializada pelo arranjo da sala, pelas metodologias ativas e participativas, e pelo ambiente horizontal, foi apontada como um importante componente da disciplina. Isso atribui às metodologias ativas e participativas a qualidade de serem inclusivas, já que se utilizam da diversidade como um componente no processo de ensino-aprendizagem (GUASP, MEDINA; AMENGUAL, 2020)

Esse destaque da diversidade feito pelos estudantes foi um resultado também encontrado por Silva et al. (2014). Os autores apontam que a "riqueza das diferenças" (p.11) gerou um resultado "mais qualificado e significativo" (p.11) para a aprendizagem dos estudantes individualmente e coletivamente.

Nesta pesquisa, a percepção da importância da convivência pelos estudantes foi reafirmada pelo fato de a unidade de ideia 'estar com o outro' ter sido a que foi mais destacada nos textos dos estudantes, como mostra o quadro 1. Essa unidade abrange menções dos estudantes relativas aos efeitos, em si e nas suas opiniões, produzidos pelas possibilidades de conversa, de convívio e de aprendizado junto aos demais colegas e a equipe docente. Como pode ser visto nos excertos, o exercício da empatia, da compreensão e da alteridade, a sensação de estranhamento, conforto e desconforto decorrente da participação coletiva, a lida com o outro, a percepção da insubstituibilidade dos debates em sala, a proximidade do calor humano, a confiança no outro, o reconhecimento do valor do diálogo e da possibilidade de aprendizagem e reinterpretação coletiva, são elementos que indicam a importância da convivência propiciada e fomentada pelas metodologias ativas participativas da disciplina. 
Essa unidade de ideia reitera a importância da estética, da afetividade, da sensibilidade e da reafirmação das subjetividades para a aprendizagem. Da mesma forma, a importância da presença do outro e do processo de construção de confiança com ele, que pode favorecer nos estudantes a emergência de um senso de pertencimento e da aprendizagem como um processo prazeroso (BORBA; ALVES; CAMPAGNOLO, 2020).

Desse modo, sobre essa unidade de ideia, duas questões são destacadas. A primeira, a ênfase na convivência com o outro como uma experiência formativa (MICHAEL, 2006; FORMENTI; JORIO, 2019). Juntos, estudantes têm uma interação maior (GÓMEZ-POYATO, 2019) e a possibilidade de olhar o conteúdo a partir de diferentes lentes, o que pode gerar reflexões que podem ser incorporadas e combinadas na construção e reconstrução de sentidos (MICHAEL, 2006). Isso reforça que relações pessoais são cruciais (MARTINS et al. 2019; BORBA; ALVES; CAMPAGNOLO, 2020) e, como colocam Rodríguez et al. (2019), que colaboração, troca de ideias e diferentes perspectivas são ingredientes fundamentais para a construção do conhecimento. Para Formenti e Jorio (2019), as capacidades de problematizar, pesquisar e resolver problemas desenvolvem-se e concretizam-se através do diálogo. Para que isso ocorra, no entanto, é necessário um ambiente seguro, pois o desconforto da lida com o inesperado pode levar estudantes a sentir emoções limítrofes e se retrair (FORMENTI; JORIO, 2019).

A segunda questão emergente da unidade 'estar com o outro' está relacionada a como, em um ambiente participativo e ativo, vários outros aspectos são estimulados e exercitados, para além do conteúdo. Isso leva essas metodologias a serem associadas a processos educativos integrais e mais abrangentes (MARTINS et al. 2019; HERNÁNDEZ; ORTIZ; ABELLÁN, 2020), e como visto no contexto desta pesquisa, a propiciar a transcendência da dimensão da informação e o alcance de aprendizagens mais complexas (BISSOTO; CAIRES, 2019).

Esse contexto que está se desenhando acima, de um ambiente onde o estudante pode participar ativamente de debates, tem voz e ouvidos, se sente protagonista e autônomo, foi associado à percepção do 'pensamento crítico', a sexta unidade de ideia construída. No quadro 1, vê-se que alguns estudantes mencionaram o desenvolvimento da sua criticidade, e o fizeram de modo relacionado à interação coletiva. No excerto destacado, por exemplo, a estudante aponta o pensamento crítico como algo considerado pouco acessível, mas que pode ser democratizado a partir de iniciativas participativas.

A associação entre metodologias ativas e participativas e 0 desenvolvimento do pensamento crítico é encontrada em Lin e Hwang (2018), Polo et al. (2019), Rodríguez et al. (2019), Wiltbank et al. (2019), Zamar e Segura (2020), entre outros. Por meio dessas metodologias, estudantes podem ser colocados em situações de enfrentamento de problemas reais, de indagação (GUASP, MEDINA; AMENGUAL, 2020), podem participar de jogos, simulações, investigações, discussões, trabalhos colaborativos (RODRÍGUEZ

Revista brasileira educação ambiental 
et al, 2019), combinar e comparar o que fazem e pensam com os colegas (MICHAEL, 2006), refletir sobre o que pensam (BENZANILLA et al. 2019) e produzir novos significados (BISSOTO; CAIRES, 2019). Isso configura processos em que eles se envolvem cognitiva, sensitiva e emocionalmente, o que favorece a formação do pensamento crítico (BISSOTO; CAIRES, 2019).

A intenção de ação das metodologias ativas dialoga com a crítica à passividade presente na centralidade nos conteúdos. Isso se relaciona à obra de Freire (1987), que aponta a importância do pensamento crítico para a emancipação e consciência de si no mundo. Desse modo, as metodologias, dependendo do pano de fundo teórico sob o qual são praticadas, podem contribuir para uma ação que extrapole o estudante e sua ação mental e corporal, possibilitando articulações coletivas, que fomentem ações fora da sala de aula.

A sétima unidade de ideia reúne excertos de nove textos que estabelecem uma 'relação metodologia - conteúdo'. Essa relação foi feita de três maneiras. A primeira, através do reconhecimento da coerência entre o uso de metodologias ativas e participativas e as características da questão ambiental, que deve ser "holística, plural, coletiva, contraditória e propositiva". A importância de se criarem metodologias coerentes com os propósitos de uma disciplina é discutida por Moran (2015), sob a pena da metodologia não propiciar caminhos para o alcance da formação que almeja.

A segunda, quando estudantes refletem especificamente sobre a metodologia vivenciada, de forma que ela se torna um conteúdo. Nos textos, estudantes abordaram questões epistemológicas e teóricas a partir de reflexões sobre a metodologia. No repertório teórico das metodologias ativas, alguns autores afirmam que metodologias não são neutras, mas compõem a disciplina junto com os conteúdos (MICHAEL, 2006; PAIVA et al. 2016). No entanto, nesta pesquisa, um aspecto a mais foi constatado, de que as metodologias podem ser formativas por si só, pois a vivência nelas pode levar ao desenvolvimento de reflexões independentemente do conteúdo abordado.

A terceira consiste no fato de o conteúdo não ter sido negligenciado pelo uso de metodologias ativas e participativas. Isso foi observado nas narrativas dos estudantes de duas formas, por menções explícitas e pelo uso dos referenciais teóricos propostos pelo professor, indicando apropriação do conteúdo.

Outra questão presente nos textos foi a 'crítica' a aspectos negativos da disciplina, relacionados à quantidade demandada de trabalho extraclasse, que concorreu com exigências de outras disciplinas e com a vida profissional dos estudantes. Consequências destacadas disso foram desânimo, vontade de desistir e incapacidade de tirar maior proveito da disciplina.

Apesar dessas implicações negativas terem sido levantadas por apenas dois dos trabalhos, seu destaque foi feito porque essa é uma questão que merece reflexão por proponentes de metodologias ativas e participativas. 
De fato, muitas críticas a elas estão relacionadas à quantidade de tempo que exigem dos estudantes (SILVA et al. 2014; DÍAZ; MARTÍN, 2018; RODRÍGUEZ et al. 2019; LUCENA et al. 2019; GALINDO-DOMÍNGUEZ; BENZANILLA, 2019), de forma que se todas as disciplinas trabalhassem dessa maneira, ficaria impraticável para eles (DÍAZ; MARTíN, 2018). É necessário, assim, que a quantidade de trabalho seja balanceada, de forma a não comprometer 0 engajamento dos estudantes (RODRÍGUEZ et al. 2019).

Mais um aspecto que precisa ser levado em consideração é que os estudantes, para serem capazes de se engajar nas atividades presenciais, precisam acompanhar o repertório da disciplina. Caso contrário, correm o risco de uma exclusão presencial (WILTBANK et al. 2019). Isso é relevante sobremaneira para disciplinas como a estudada, com estudantes de diferentes cursos, origens socioeconômicas, faixas etárias, vivências acadêmicas (alguns calouros, outros em períodos finais de curso e outros já em sua segunda graduação) e condições de se dedicarem às atividades extra classe.

Por fim, a nona unidade de ideia construída, 'mudanças/autoanálise', reúne associações feitas por quatro estudantes entre vivências com as metodologias ativas e participativas e a autopercepção de mudanças no modo de ser e/ou ver o mundo. Nesse aspecto, estudantes explicitaram mudanças de percepção sobre o papel de disciplinas acadêmicas e o seu papel dentro de uma disciplina, transcendendo a memorização e contemplando o questionamento, o compartilhamento e a reflexão. Também, enfatizaram a diferença entre assistir e participar ativamente de uma aula, e destacaram melhora em habilidades pessoais como na comunicação, expressão e interação com outros estudantes. Esse processo de autoanálise indicou, por outro lado, incômodos relacionados a metodologia, expressos pelos estudantes como "saída da zona de conforto" e "sentimento de repulsa" diante das aulas participativas.

A influência das metodologias ativas e participativas sobre a percepção de estudantes a respeito de seus modos de ser e/ou ver o mundo também está registrada em outros trabalhos. Por exemplo, Pintado, Robas e Rey-Baltar (2018) as associam à melhora da convivência e de habilidades sociais, e ao alcance de objetivos afetivo-emocionais. Martins et al (2019), Wiltbank et al. (2019) e Zamar e Segura (2020), à melhora na comunicação. E Bissato e Caires (2019) as vinculam à auto-implicação nas aulas e à ampliação da crença dos estudantes na sua capacidade de aprender.

\section{Metodologias e narrativas de aprendizagem: entrelaces com o campo da EA}

As metodologias ativas e participativas estão cada vez mais presentes no ensino superior, em diferentes cursos e disciplinas. Na literatura, porém, nenhum trabalho foi encontrado relativo especificamente à EA. No entanto, pressupostos, caminhos e intenções dessas metodologias, já observados em outros campos do conhecimento, dialogam com o que propõem documentos de referência da EA, como a PNEA (BRASIL, 1999), o ProNEA (BRASIL, 2005; 
2018), o Tratado de Educação Ambiental para Sociedades Sustentáveis e Responsabilidade Global (FÓRUM..., 1992) e as diretrizes curriculares para a EA (BRASIL, 2012). Esses princípios e intenções são difíceis de serem realizados por práticas bancárias (FREIRE, 1987). Assim, uma investigação se fazia necessária quanto ao potencial dessas metodologias para a EA no ensino superior.

Os resultados deste trabalho apontam que o uso das metodologias ativas e participativas favoreceu espaços em que a vivência democrática e algumas de suas mazelas, como o exercício da convivência na diversidade e na horizontalidade, o desconforto diante do outro, a participação protagonista e o ouvir, foram exercitadas. Isso é importante pois, segundo Lewin (1989), a democracia não está dada, precisa ser construída e garantida no dia a dia. $\mathrm{Da}$ mesma forma, houve o chamamento à responsabilização dos estudantes por suas aprendizagens.

Também, favoreceu a experiência estética de reconhecer o diferente (SATO; QUADROS; KAWAHARA, 2018), de se afetar por outros corpos (PAYNE et al. 2018), de se sentir pertencente (SANTOS; GUIMARÃES, 2020), e de acessar a realidade por diferentes lentes, elementos importantes para uma leitura do mundo a partir do ponto de vista ambiental (CARVALHO, 2012).

Além disso, estudantes destacaram o desenvolvimento de algumas competências, como o senso crítico, a capacidade de comunicação, de expressão, de auto engajamento e a interação com outros estudantes. Algumas dessas competências não estão previstas como princípios ou objetivos da EA, mas são fundamentais no diálogo com outras culturas e na formação integral dos estudantes, que por sua vez retroalimenta suas capacidades de participação pública, ou seja, sua formação cidadã.

Esse resultado indica que o uso de metodologias ativas e participativas em uma disciplina de EA no ensino superior pode fazer dela uma disciplina performática, em que os estudantes experienciam e exercitam no dia a dia aspectos da teoria que estudam, ao mesmo tempo em que formam ou fortalecem valores e competências que são almejadas para a sua formação.

\section{Considerações finais}

Os resultados deste trabalho demonstram que os estudantes relacionaram a sua experiência com a metodologia à sua aprendizagem por meio de momentos textuais que foram sistematizados em nove unidades de ideias: críticas ao ensino tradicional, arranjo da sala, horizontalidade, diversidade, estar com o outro, pensamento crítico, relação metodologiaconteúdo, críticas e mudanças/autoanálise.

Além disso, demonstram que o uso das metodologias ativas e participativas não alterou apenas o papel de docentes e alunos, mas também o da sala de aula e seus móveis, dos conteúdos (que deixaram de ser apenas 
fins, para serem também meios), e das próprias metodologias, (que deixaram de ser apenas meios, para serem também fins, já que têm o potencial para serem formativas por si só).

Da mesma maneira, o uso das metodologias ativas e participativas favoreceu a construção de um ambiente de exercício democrático e participativo e o desenvolvimento de competências (o senso crítico, a comunicação, a expressão, o engajamento nos estudos e o protagonismo), de valores (horizontalidade, diversidade, alteridade, papel formativo de estar com outro, estudar para o autodesenvolvimento), de habilidades sociais (ouvir e conviver com o diferente), e o alcance de objetivos afetivo-emocionais (calor humano, confiança, compreensão, empatia e respeito). Muitas dessas competências, valores, habilidades e objetivos são propostos por documentos de referência e autores da EA brasileira, o que tornou a disciplina coerente, na prática, com seu próprio discurso. Isso aponta que as metodologias ativas e participativas oferecem um caminho promissor para processos educativos de EA no ensino superior, assim, como para a investigação desses processos.

\section{Agradecimento}

À Pró Reitoria de Graduação da Universidade Federal do Estado do Rio de Janeiro pela bolsa de monitoria disponibilizada para a disciplina Educação Ambiental e Cidadania, que possibilitou essa pesquisa.

\section{Referências}

ANDRADE, D. F. de; FIGUEIREDO, T. F. A formação de educadores ambientais: concepção teórico-metodológica de uma disciplina no ensino superior. In: GONÇALVES, H. J. L.; BRANCALEONI, A. P. L. (Org.). Pesquisa, Ensino \& Processos Formativos. Porto Alegre: Fi, 2019, v. 5, p. 125-138.

BEZANILLA, M.J. et al. Methodologies for teaching-learning critical thinking in higher education: The teacher's view. Thinking Skills and Creativity, v. 33, 2019.

BISSOTO, M. L.; CAIRES, S. Metodologias ativas e participativas: seus contributos para o atual cenário educacional. Práxis Educacional, [S. I.], v. 15, n. 35, p. 161-182, 2019.

BORBA, G.S. de; ALVES, I.M.; CAMPAGNOLO, P.D.B. How learning spaces can collaborate with student engagement and enhance student-faculty interaction in higher education, Innovative Higher Education, 45, p. 51-63, 2020.

BRASIL. Educação Ambiental por um Brasil sustentável: ProNEA, marcos legais e normativos. Brasília: MMA, 2018. 
BRASIL. Resolução no 2, de 15 de junho de 2012. Estabelece as Diretrizes Curriculares Nacionais para a Educação Ambiental. Disponível em: $<$ http://portal.mec.gov.br/dmdocuments/rcp002 12.pdf>. Acesso 14 mai. 2020.

BRASIL. Programa Nacional de Educação Ambiental. MMA/DEA/MEC/CGEA, 3. ed. Brasília: MMA, 2005.

BRASIL. Lei n. 9.795 de 27 de abril de 1999. Dispõe sobre a Educação Ambiental, institui a Política Nacional de Educação Ambiental e dá outras providências. Brasília: Diário Oficial da União, 28 de abril de 1999. Disponível em: <http://www.planalto.gov.br/ccivil 03/leis/19795.htm>. Acesso em: 01 ago. 2020.

BRASIL. Constituição da República Federativa do Brasil. Brasília: Diário Oficial da União, 05 de outubro de 1988. Disponível em: $<$ http://www.planalto.gov.br/ccivil 03/constituicao/constituicao.htm>. Acesso em 01 de ago. 2020

BRASIL. Lei Ordinária 6.938 de 31 de agosto de 1981. Dispõe sobre a política nacional do meio ambiente, seus fins e mecanismos de formulação e aplicação, e dá outras providências. Diário Oficial da União, 02/09/1981, p. 16509.

CARSTENSEN, S.S. et al. Implementing collaborative, active learning using peer instructions in pharmacology teaching increases students' learning and thereby exam performance. European Journal of Pharmacology, v. 867, 2020.

CARVALHO, I. C. de. M. Educação Ambiental e a formação do sujeito ecológico. 6.ed. São Paulo: Cortez, 2012.

DÍAZ, M.J.S.; MARTíN, R.F.P. Flipped classroom en la formación inicial del profesorado: perspectiva del alumnado. Revista de Docencia Universitaria, v. 16, n. 2, p. 249-264, 2018.

$\mathrm{DU}, \mathrm{X}$. et al. Active learning engagement in teacher preparation programmes A comparative study from Qatar, Lebanon and China. Asia Pacific Journal of Education, 2020.

FREIRE, P. Pedagogia do oprimido. Rio de Janeiro: Paz e Terra, 1987.

FORMENTI, L.; JORIO, F. Multiple visions, multiple voices: a dialogic methodology for teaching in higher education. Journal of Transformative Education, v. 17, n. 3, p. 208-227, 2019.

FÓRUM INTERNACIONAL DAS ORGANIZAÇÕES NÃO GOVERNAMENTAIS E MOVIMENTOS SOCIAIS. Tratado das ONGs. Rio de Janeiro, 1992.

GALINDO-DOMÍNGUEZ, H.; BENZANILLA, M.J. Una revisión sistemática de la metodología flipped classroom a nivel universitario en España. International Journal of Technology and Educational Innovation, v.5, n.1., p.81-90, 2019.

GALLO, S. O aprender em múltiplas dimensões. Perspectivas da educação matemática, v. 10, n. 22, 2017. 
GEE, J. P. How to do Discourse Analysis: a toolkit. 3ed. Nova York: Routledge, 2011.

GEE, J. P. A linguistic approach to narrative. Journal of Narrative and Life History, v. 1.1, p. 15-39, 1991.

GIOIOSA, M.E.; KINKELA, K. Active learning in accounting classes with technology and communication skills: A two-semester study of student perceptions. Journal of Education for Business, vol. 94, n. 8, p. 561-568, 2019.

GÓMEZ-POYATO, M.J. et al. Flipped classroom and role-playing as active learning methods in the social work degree: randomized experimental study. Social Work Education, 2019.

GUASP, J.J.M.; MEDINA, C. P.; AMENGUAL, B. M. El impacto de las metodologías activas en los resultados académicos: un estudio de casos. Revista de Currículum y Formación del Profesorado, v. 24, n.1, Feb. 2020.

HERNÁNDEZ, D.J.; ORTIZ, J.J.G.; ABELLÁN, M.T. Metodologías activas en la universidad y su relación con los enfoques de enseñanza. Revista de Currículum y Formación del Profesorado, v.24, n.1, Feb. 2020.

KAUFMANN, J.J. The practice of dialogue in critical pedagogy. Adult Education Quarterly. v. 60, n. 5, p. 456-476, 2010.

KOELLING, S. B. Os dêiticos e a enunciação. Revista Virtual de Estudos da Linguagem. v. 1, n. 1, agosto de 2003.

LAYRARGUES, P.P. (Coord). Identidades da Educação Ambiental brasileira. MMA/DEA. Brasília: Ministério do Meio Ambiente, 2004.

LEWIN, K. Problemas de dinâmica de grupo. 9. ed. São Paulo: Cultrix, 1989.

LIN, C.-J.; HWANG, G.-J. A learning analytics approach to investigating factors affecting efl students' oral performance in a flipped classroom. Educational Technology \& Society, v.21, n. 2, p. 205-219, 2018.

LUCENA, L.J.H. et al. Influencia del aula invertida en el rendimiento académico. Una revisión sistemática. Campus Virtuales, v. 8, n. 1, p. 9-18, 2019.

MARTINS, A.O. et al. Metodologias ativas para a inovação e qualidade do ensino e aprendizagem no ensino superior. Revista Educação a Distância e Práticas Educativas Comunicacionais e Interculturais, v.19, n.3, p.122-132, set./dez. 2019.

MICHAEL, J. Where's the evidence that active learning works? Adv Physiol Educ, v. 30, p. 159-167, 2006.

MORAN, J. Mudando a educação com metodologias ativas. In: SOUZA, C.; MORALES, O.E.T. (Orgs). Convergências Midiáticas, Educação e Cidadania: aproximações jovens. PG: Foca Foto-PROEX/UEPG, 2015.

PAIVA, M.R.F. et al. Metodologias ativas de ensino-aprendizagem: revisão integrativa. SANARE, Sobral, v.15 n. 2, p.145-153, Jun./Dez, 2016. 
PAYNE, P. et al. Affectivity in Environmental Education Research. Pesquisa em Educação Ambiental, v. 13, especial, p. 93-114, 2018.

PINTADO, A.G.; ROBAS, V.R.; REY-BALTAR, A.Z. Implementación de metodologías cooperativas en la docencia universitaria: experiencias en la Facultad de Educación y Deporte de Vitoria-Gasteiz. Revista de Currículum y Formación del Profesorado, v. 22, n. 3, Sep. 2018.

POLO, F.Z. et al. Nonscientific university students training in general science using an active-learning merged pedagogy: gamification in a flipped classroom. Educ. Sci. 9, 297, 2019. .

REIGOTA, M. Educação Ambiental: fragmentos de sua história no Brasil. In: NOAL, F.O.; REIGOTA, M; BARCELOS, V.H. de L. Tendências da Educação Ambiental brasileira. Santa Cruz do Sul: Edunisc, 1998, p.11 - 25.

RODRíGUEZ, G. et al. Flipped classroom: Fostering creative skills in undergraduate students of health sciences. Thinking Skills and Creativity, n. 33, 2019.

SANTOS, D. G. G. dos; GUIMARÃES, M. Pertencimento: um elo conectivo entre o ser humano, a sociedade e a natureza. REMEA - Revista Eletrônica do Mestrado em Educação Ambiental, [S.I.], v. 37, n. 3, p. 208-223, ago. 2020.

SATO, M.; QUADROS, I. Y KAWAHARA, L. Cano e festa: sonhantes artísticocientífico do pantanal de Mato Grosso. In: Tristão, M. A Educação Ambiental e o pensamento pós colonial: narrativas de pesquisas - Curitiba, PR; CRV, 2018. p. $31-48$.

SCHULTZ, D. et al. Effects of the flipped classroom model on student performance for advanced placement high school chemistry students. J. Chem. Educ, 91, p. 1334-1339, 2014.

SILVA, L. S. da et al. Formação de profissionais críticos-reflexivos: o potencial das metodologias ativas de ensino-aprendizagem e avaliação na aprendizagem significativa. Revista CIDUI, 2014.

SOUZA, E. C.; OLIVEIRA, R. C. M. Pesquisa (auto)biográfica, cultura e cotidiano escolar: diálogos teórico-metodológicos. Revista Interinstitucional Artes de Educar. Rio de Janeiro, v. 2, n. Especial, p. 182-203, jun. - out. 2016.

TEIXEIRA, D. de L.; DUARTE, M.F.; MORIMOTO, P. Manual de metodologias participativas para o desenvolvimento comunitário. São Paulo: USP, 2007.

WILTBANK, L.B. et al. Contrasting cases: students' experiences in an activelearning biology classroom. CBE Life Sci Educ. September, v.18, n.33, 2019.

ZAMAR, M. G.; SEGURA, E. A. El aula invertida: un desafío para la enseñanza universitária. Virtualidad, Educación y Ciencia, v. 20, n. 11, p. 75-91, 2020. 